\title{
Cost Effectiveness of Gastroprotection with Proton Pump Inhibitors in Older Low-Dose Acetylsalicylic Acid Users in the Netherlands
}

\author{
Sek Hung Chau ${ }^{1} \cdot$ Reinier L. Sluiter ${ }^{2} \cdot$ Wietske Kievit $^{2} \cdot$ Michel Wensing $^{3,4}$. \\ Martina Teichert ${ }^{3,5,6} \cdot$ Jacqueline G. Hugtenburg ${ }^{1}$
}

Published online: 30 March 2017

(c) The Author(s) 2017. This article is an open access publication

\begin{abstract}
Purpose The present study aimed to assess the cost effectiveness of concomitant proton pump inhibitor (PPI) treatment in low-dose acetylsalicylic acid (LDASA) users at risk of upper gastrointestinal (UGI) adverse effects as compared with no PPI co-medication with attention to the age-dependent influence of PPI-induced adverse effects.

Methods We used a Markov model to compare the strategy of PPI co-medication with no PPI co-medication in older LDASA users at risk of UGI adverse effects. As PPIs reduce the risk of UGI bleeding and dyspepsia, these risk factors were modelled together with PPI adverse effects for LDASA users 60-69, 70-79 (base case) and 80 years and older. Incremental cost-utility ratios (ICURs) were calculated as cost per quality-adjusted life-year (QALY) gained per age category. Furthermore, a budget impact analysis
\end{abstract}

S. H. Chau and R. L. Sluiter contributed equally to this work.

Sek Hung Chau

s.chau@vumc.nl

1 Department of Clinical Pharmacology and Pharmacy, VU University Medical Center, De Boelelaan 1117, 1081 HV Amsterdam, The Netherlands

2 Department for Health Evidence, Radboud University Medical Center, Nijmegen, The Netherlands

3 Scientific Institute for Quality of Healthcare (IQ Healthcare), Radboud University Nijmegen Medical Center, Nijmegen, The Netherlands

4 Department of General Practice and Health Services Research, Heidelberg University, Heidelberg, Germany

5 Department of Clinical Pharmacy and Toxicology, Leiden University Medical Center, Leiden, The Netherlands

6 Research and Development, Royal Dutch Pharmacists Association (KNMP), The Hague, The Netherlands assessed the expected changes in expenditure of the Dutch healthcare system following the adoption of PPI co-treatment in all LDASA users potentially at risk of UGI adverse effects.

Results PPI co-treatment of 70- to 79-year-old LDASA users, as compared with no PPI, resulted in incremental costs of $€ 100.51$ at incremental effects of 0.007 QALYs with an ICUR of $€ 14,671 / \mathrm{Q} A L Y$. ICURs for 60 - to 69-year-old LDASA users were $€ 13,264 / \mathrm{QALY}$ and $€ 64,121 / \mathrm{QALY}$ for patients 80 years and older. Initiation of PPI co-treatment for all Dutch LDASA users of 60 years and older at risk of UGI adverse effects but not prescribed a PPI (19\%) would have cost $€ 1,280,478$ in the first year (year 2013 values).

Conclusions PPI co-medication in LDASA users at risk of UGI adverse effects is generally cost effective. However, this strategy becomes less cost effective with higher age, particularly in patients aged 80 years and older, mainly due to the increased risks of PPI-induced adverse effects.

\section{Key Points}

Adding a proton pump inhibitor (PPI) in low-dose acetylsalicylic acid users at risk of upper gastrointestinal adverse effects was cost effective in all cases for a threshold value of $€ 64,121$.

With higher age and including the risk of adverse effects, adding a PPI became less cost effective, mainly due to the increased risks of PPI-induced adverse effects. 


\section{Introduction}

Upper gastrointestinal (UGI) adverse effects caused by low-dose acetylsalicylic acid (LDASA) often result in hospital admissions [1, 2]. Proton pump inhibitors (PPIs) are effective in preventing these adverse effects [3-5]. Therefore, Dutch guidelines recommend PPI co-treatment in LDASA users older than 80 years and in those between 70 and 80 years who take additional co-medication that increases the risk of UGI adverse effects. In LDASA users between 60 and 70 years with two additional risk factors due to co-medication or with a medical history of an ulceration, PPI co-treatment is also indicated [6, 7]. However, for various reasons, these recommendations appear to have been implemented only to a limited extent to date $[6,8]$. At the time they were issued (2009) only two-thirds of the patients at risk were prescribed any form of gastroprotective medication [9]. Since LDASA is generally intended for a lifelong use, patients at risk should use PPIs for long-term gastroprotection as well. However, the prolonged use of PPIs has been associated with adverse effects such as osteoporosis and hip fractures [10-17], pneumonia [18-23], and campylobacteriosis [24]. Although the actual risk increases were found to be modest and might have been confounded [13, 23, 25], the US Food and Drug Administration (FDA) has labelled PPIs as having a risk of osteoporosis [26]. Although the FDA has no authority in Europe, US recommendations get attention in medical and pharmaceutical journals available in the Netherlands and therefore may have consequences outside the regulatory scope of the FDA. Recommendations to use PPIs are based on clinical evidence, but as yet there are limited data on the cost effectiveness of PPI co-treatment. Since cheaper generic preparations have become widely available, PPI costs used in earlier analyses, comparing strategies of LDASA treatment with and without PPI comedication to no LDASA treatment for primary or secondary prevention, are no longer representative $[27,28]$. Accordingly, De Groot et al. [29] recently concluded that PPI co-treatment was likely to be cost effective. Since the risk of developing UGI adverse effects and the mortality risk have been found to differ in an age-dependent manner, the present recommendations to start gastroprotection in LDASA users include various age categories [6]. Moreover, recent advances in knowledge have increasingly drawn attention to the potential burden of PPI adverse effects [10-25]. The present study therefore aimed to assess the cost effectiveness of the strategy of PPI cotreatment compared with no PPI use in LDASA users at risk of UGI adverse effects, paying specific attention to potential adverse effects due to PPI use in patients of different ages. In addition, we estimated the costs of treating all LDASA users in the Netherlands who are at risk of UGI adverse effects and are currently not receiving PPI comedication.

\section{Methods}

\subsection{Model Framework}

In order to calculate the cost effectiveness of PPI comedication in LDASA users, a Markov model was developed using Microsoft Office Excel ${ }^{\circledR} 2007$ (Microsoft Corp., Redmond, WA, USA). The model compared the strategies of PPI co-medication with no PPI co-treatment in LDASA users from a healthcare perspective.

The model structure is shown in Fig. 1. A hypothetical cohort of 1000 patients entered the model in a health state without UGI symptoms. Through a series of 3-month Markov transition cycles, the cohort was followed over a 5-year time horizon. In a 3-month cycle, patients could stay in this health state or develop dyspepsia, gastrointestinal bleeding, hip fractures, pneumonia or might die. Patients could return to the 'healthy state' after dyspepsia occurred, but they transferred to a 'post' health state after gastrointestinal bleeding. From a 'post' state, subjects may still develop other complications (e.g. dyspepsia or recurrent gastrointestinal bleeding) or hip fracture and pneumonia, but could never return to the "healthy state'. Their risk for re-bleeding and dyspepsia increased under the model assumptions. We chose a cycle length of 3 months because of the rather short duration of the modelled adverse effects. After 3 months patients should be able to transit to a post-adverse effect health state and have a probability of developing another adverse effect. For the strategy without PPI co-medication, for subjects in the 'post' state Initiation of PPI treatment was assumed which resulted in a risk reduction of UGI adverse effects and costs. We assumed there was continuous use of a PPI during 5 years at a compliance rate of $68 \%$, to reflect clinical practice [30]. Full adherence was assumed for LDASA.

\subsection{Model Parameters}

Model parameters were retrieved from recent studies addressing LDASA use with PPI co-medication that had the parameters and source clearly stated, preferably conducted in the Netherlands. Most parameters for the model could be derived from two different studies by De Groot et al. [29, 30] describing risk parameters, cost estimates and utilities related to UGI adverse effects. These models were identified by searching for models comparing the strategy of PPI co-medication with no PPI in LDASA/non-steroidal anti-inflammatory drug (NSAID) users that were published 
Fig. 1 Markov model structure for the effects of proton pump inhibitor co-medication in lowdose acetylsalicylic acid users at increased upper gastrointestinal risk. A cohort of 1000 patients was modelled for a period of 5 years. Each patient started in a healthy state, and in each 3-month cycle patients could enter one of the other health states (dyspepsia, gastrointestinal bleeding, hip fracture, pneumonia or death) or stay healthy. Patients could develop a hip fracture or pneumonia after each health state. GI gastrointestinal

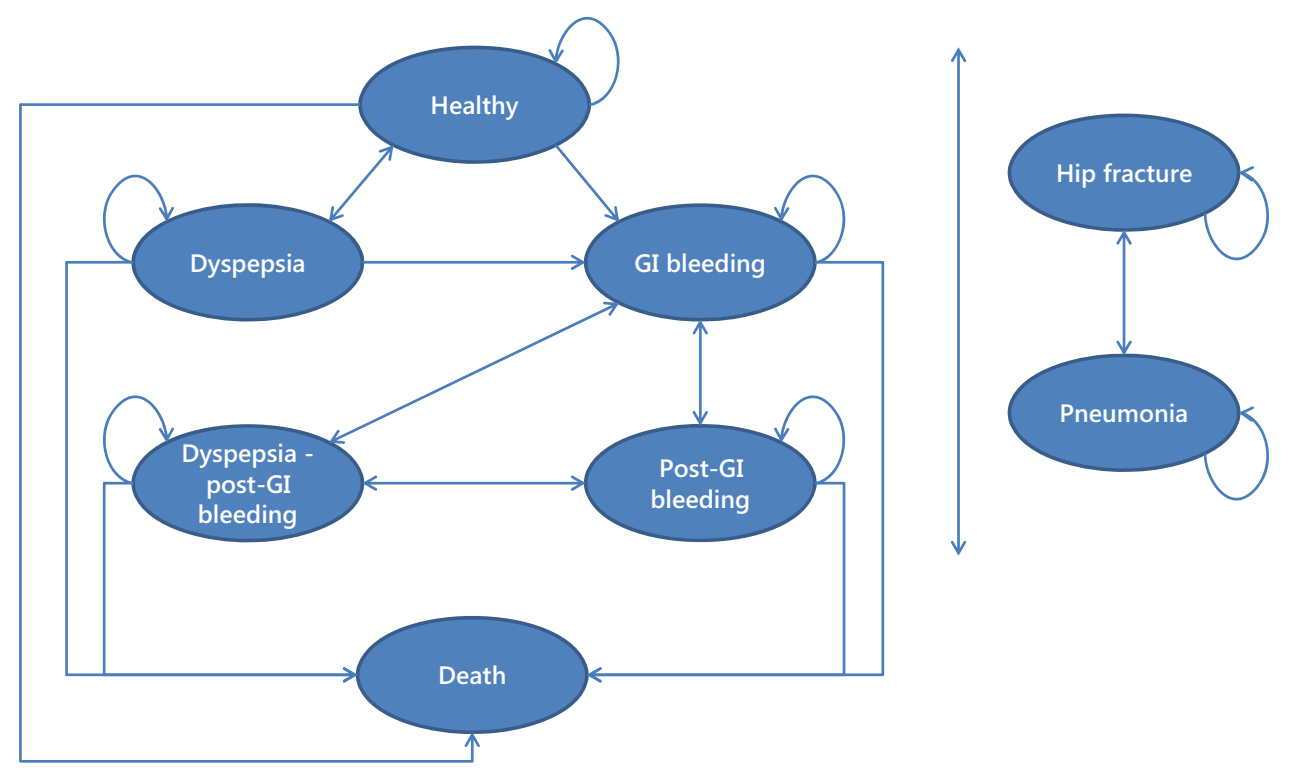

over the last 10 years, and contained the most recently published scientific data. As the transition probabilities in these studies were for 1-year cycles, they were transformed into 3-month specific probabilities [31]. Whenever possible, parameter risks were modified for effects related to increasing age (probabilities of developing a peptic ulcer bleeding [PUB], of pneumonia due to PPI, of hip fracture due to PPI; the general mortality rate; and the chance of PUB while using LDASA). The utilities related to the different health states were used to calculate quality-adjusted life-years (QALYs) [32]. Most of the cost estimates used by De Groot et al. [29, 30] were used except for medication costs, which were collected from the Dutch National Health Care Institute [33]. Parameters and costs retrieved from these studies were updated when necessary; these are all given in Appendix A.

The risk of hip fractures and pneumonia due to PPI use was estimated in two steps. First, information on incidence rates in the general population for hip fracture and pneumonia was derived from recent Statistics Netherlands data [34]. Second, these rates were multiplied by PPI-specific risk ratios collected from the literature on increased risks of hip fracture [10] and pneumonia [18]. Cost estimates for the health states of pneumonia [35] and hip fracture [36] were derived from the literature (Appendix A).

\subsection{Analysis}

\subsubsection{Base-Case Analysis}

The base case cohort of 70- to 79-year-old patients consisted of 1000 LDASA users. Costs were discounted at an annual rate of $4 \%$ and utilities at an annual rate of $1.5 \%$ according to the Dutch guidelines for pharmacoeconomic evaluation [37]. Parameter uncertainty was examined with Monte-Carlo simulations of 5000 iterations. Within each iteration, values for the model parameters in question were randomly selected from their distribution [32], characterised by $95 \%$ confidence intervals (CIs) and standard errors [29, 30]: beta distributions were used for probability and utilities, gamma distributions for costs and lognormal distributions for risk ratios [31].

Based on Monte-Carlo simulations, the difference in costs and QALYs between the strategy of using PPI comedication and no PPI co-medication was expressed as an incremental cost-utility ratio (ICUR) for each iteration. Of the 5000 iterations, the 2.5 th and 97.5 th percentiles were determined for the incremental costs and effects and presented as scatter plots of incremental costs and effects, and cost-effectiveness acceptability (CEA) curves. CEA curves were constructed to estimate the probability that PPI comedication was cost effective given different cost-effectiveness thresholds. In addition to the base case, ICURs were also estimated for LDASA users 60-69 years old and 80 years old and above, according to the guideline age thresholds for the risk of UGI adverse effects $[6,7]$.

\subsubsection{Sensitivity Analysis}

One-way sensitivity analysis was performed to assess the effects of the different model parameters on the cost effectiveness of PPI co-medication. They are shown in tornado diagrams for the effect of parameter values of the 5th and 95th percentiles on the net monetary benefit (NMB). The incremental NMB shows the difference between PPI co-medication and no PPI use in LDASA users at risk as a monetary value. This was calculated as the maximum amount an individual is willing to pay for a unit 
or effect (QALY), the so-called willingness to pay (WTP), minus the difference in costs of both strategies [32]. The WTP assumed here was $€ 30,000$, as an example, to showcase the influences of the parameters.

\subsubsection{Scenario Analysis}

Furthermore, scenario analyses with and without costs for adverse effects were performed. In these different scenarios, pneumonia and hip fracture were taken into account separately or not at all. Incremental costs and effects and subsequent ICURs were calculated per scenario. Scenario analyses were also performed for the discount rates, where both costs and effects were discounted at the same rate [32], and for the compliance rate in order to estimate the influence of both parameters. For both parameters, there is considerable controversy about their weight and whether they should be included or not. Therefore, their influence is investigated in these scenarios.

\subsubsection{Budget Impact Analysis}

Finally, a budget impact analysis (BIA) was performed according to international guidelines $[37,38]$ to calculate the costs of PPI co-treatment in LDASA users at risk but without actual gastroprotective PPI co-medication. In order to calculate the budget impact, the cost-effectiveness model of this study was used. Therefore, this BIA was performed from a healthcare perspective (only healthcare costs included) with a time horizon of 1 year. With this model the costs of the usual care without PPIs, and subsequently the costs related to care with PPI use, could be calculated. The difference in costs was used in the BIA. Subsequently, the number of potential PPI users in the Dutch population was estimated on the basis of Dutch Foundation of Pharmaceutical Statistics (SFK) data. SFK collects dispensing data from $95 \%$ of the 1980 Dutch community pharmacies. These data contain detailed information on the drugs dispensed, including the codes from the Anatomic Therapeutic Chemical (ATC) system of the World Health Organization [39], prescribed dose, and amount dispensed. Information on patient sex and year of birth is also available. Medication of a specific patient over time was tracked within an individual pharmacy by a unique anonymous code for each patient. Drug exposure episodes were calculated by dividing the number of drug units dispensed by the prescribed daily dose. Increased risk of UGI adverse effects was assessed according to the recommendations for LDASA users of 80 years or older, those between 70 and 80 years using other antithrombotic agents, oral corticosteroids, selective serotonin reuptake inhibitors or spironolactone co-medication, and for LDASA users between 60 and 70 years with two additional risk factors from co-morbidity or co-medication [6]. The following ATC codes were used for the different drug classes: LDASA (B01AC06, B01AC08 and B01AC30); other antithrombotics-clopidogrel (B01AC04), prasugrel (B01AC22), ticagrelor (B01AC24) and coumarins (B01AA); glucocorticosteroids for oral use (H02AB); selective serotonin reuptake inhibitors (N06AB, N06AX16, N06AX05 and N06AX21); spironolactone (C03DA01); and PPIs (A02BC).

The BIA was first calculated per age category, because at different ages different costs were made due to a differential use of health resources. Eventually, the total sum of all categories was considered as the budget impact related to implementation of PPIs.

\section{Results}

Table 1 gives the results of the cost-effectiveness analysis for the complete model for LDASA users 60-69, 70-79 and $\geq 80$ years. The results of the base case show that PPI co-medication achieves 0.007 QALYs at a cost of $€ 100.51$ compared with no PPI co-medication in LDASA users. This resulted in an ICUR of $€ 14,671$ per QALY gained. ICURs for PPI co-medication compared with no PPI use in the 60-69 and 80 years and older groups amounted to $€ 13,264$ and $€ 64,121$, respectively.

Figure 2 gives the results of the Monte-Carlo simulations for LDASA users for the three age categories within the different panels as scatterplots and CEA curves. Most dots are in the north-eastern quadrant for the base case of 70-79 years old, meaning a positive effect (gain in QALY) with positive costs (increased costs). The CEA for 70- to 79-year-old LDASA users shows that PPI co-medication has a $50 \%$ chance of being a cost-effective strategy at a WTP threshold of $€ 19,000$ per QALY gained (Fig. 2d). For the subgroup of 80 years and older LDASA users, most dots on the scatter plots also lay in the north-eastern quadrant. In the results for 70 - to 80 -year-old users, the dots lay higher and more to the left, which means higher incremental costs and fewer incremental effects gained by adding a PPI. This resulted in a WTP threshold of $€ 80,000$ for PPI co-medication with a $50 \%$ chance of being cost effective on the CEA curve (Fig. 2f).

The results of the scenario analyses related to the adverse effects are shown in Table 1. PPI co-medication was always cost effective at a WTP threshold of $€ 64,121$, even when adverse effects were taken into account. However, the ICUR was higher in the model accounting for adverse effects for all age categories. In cases where adverse effects were not taken into account, PPI co-medication 'dominated' (lower costs and more effects) the strategy of not adding a PPI for LDASA users 80 years and older. 
Table 1 Cost effectiveness for the strategy of proton pump inhibitor co-medication compared with no proton pump inhibitor use in low-dose acetylsalicylic acid users for different age categories and sensitivity analysis for the influence of proton pump inhibitor adverse effects

\begin{tabular}{|c|c|c|c|c|c|c|c|}
\hline \multirow[t]{2}{*}{ Age category } & \multicolumn{2}{|l|}{ Costs $(€)$} & \multirow[t]{2}{*}{ Incremental costs $(€)$} & \multicolumn{2}{|c|}{ QALYs } & \multirow[t]{2}{*}{ Incremental QALYs } & \multirow[t]{2}{*}{$\operatorname{ICUR}(€)$} \\
\hline & PPI & No PPI & & PPI & No PPI & & \\
\hline \multicolumn{8}{|c|}{ Complete model with both adverse effects } \\
\hline 60 years & 521.35 & 438.39 & 82.96 & 4.702 & 4.695 & 0.006 & 13,264 \\
\hline 70 years & 961.48 & 860.97 & 100.51 & 4.550 & 4.543 & 0.007 & 14,671 \\
\hline 80 years & 2733.31 & 2457.71 & 275.59 & 4.041 & 4.036 & 0.004 & 64,121 \\
\hline \multicolumn{8}{|c|}{ Model with only adverse effect pneumonia } \\
\hline 60 years & 511.70 & 438.39 & 73.31 & 4.702 & 4.695 & 0.006 & 11,360 \\
\hline 70 years & 921.68 & 860.97 & 60.71 & 4.551 & 4.543 & 0.008 & 7745 \\
\hline 80 years & 2534.66 & 2457.71 & 76.94 & 4.046 & 4.036 & 0.009 & 8441 \\
\hline \multicolumn{8}{|c|}{ Model with only adverse effect hip fracture } \\
\hline 60 years & 506.10 & 438.39 & 67.71 & 4.702 & 4.695 & 0.006 & 10,620 \\
\hline 70 years & 914.17 & 860.97 & 53.20 & 4.550 & 4.543 & 0.007 & 7223 \\
\hline 80 years & 2634.41 & 2457.71 & 176.70 & 4.043 & 4.036 & 0.006 & 28,046 \\
\hline \multicolumn{8}{|c|}{ Model with no adverse effects } \\
\hline 60 years & 496.45 & 438.39 & 58.06 & 4.702 & 4.695 & 0.007 & 8830 \\
\hline 70 years & 874.35 & 860.97 & 13.39 & 4.551 & 4.543 & 0.008 & 1602 \\
\hline 80 years & 2435.55 & 2457.71 & -22.16 & 4.048 & 4.036 & 0.011 & 'Dominates' \\
\hline
\end{tabular}

ICUR incremental cost-effectiveness ratio, PPI proton pump inhibitor, QALYs quality-adjusted life-years

When the discount rates for both costs and effects were $4 \%$, the ICUR of the base case was $€ 15,792$. For the age categories of 60-69 years and 80 years and older, the ICURs were $€ 14,241$ and $€ 68,294$, respectively. If the compliance rate was varied between the extremes of the 95\% CI (20\% and 100\%), the ICURs for the base case were $€ 73,186$ and $€ 9391$, respectively.

In the tornado diagrams (Fig. 3), the ranges, and subsequently the influence of the different adverse effects on the incremental NMB, are shown for the base case as well as for 80-year-old LDASA users. For 80-year-old LDASA users the estimates for the costs and risks of hip fracture became important influencers of the incremental NMB as compared with the base case.

Table 2 gives the results from the BIA of adding PPIs to all LDASA users at risk in the Netherlands who were not concomitantly using a PPI. According to SFK data in 2014, $19 \%$ of LDASA users 60 years or older in the Netherlands did not have PPI co-medication. This percentage rose from $8.6 \%$ (60-69 years) to $13.8 \%$ ( $70-79$ years) to $22.1 \%$ ( $\geq 80$ years). Implementing the use of PPI co-medication resulted in a budget impact of $€ 1,280,477$.

\section{Discussion}

PPI co-medication in LDASA users at risk of UGI adverse effects appeared to be cost effective, even when costs caused by potential PPI adverse effects were taken into account. However, the WTP threshold for a $50 \%$ chance of cost effectiveness for 80-year-old patients was about $€ 80,000$ per QALY. In the base case the same threshold was reached at a WTP of less than $€ 20,000$ per QALY. This clearly shows that LDASA users older than 60 years cannot be considered a homogenous group regarding the cost effectiveness of care strategies. The ICUR for costs per QALY gained increased correspondingly with age: for 80 years and older patients the costs were $383 \%$ higher than for 60- to 69 -year-olds and $337 \%$ higher than the base case. However, when adverse effects were not taken into account, the strategy of PPI co-medication appeared to be a 'dominant' strategy (lower costs and more effect) compared with no PPI in patients 80 years and older. In this respect, the results of the present study are in line with those of a previous study [29]. For the base case of 60- to 69-year-old patients, PPI co-medication was found to be cost effective at a threshold of $€ 10,000$ per QALY gained, comparable with the $€ 13,000 / \mathrm{QALY}$ in the present study. The higher costs in the present study are brought about by costs for PPI adverse effects.

Differences between the age categories were mainly caused by the consequences of PPI adverse effects, which had a higher impact in the older age categories. Since PPI co-medication in LDASA users is intended for long-term use, costs for potential adverse effects should be taken into account [40]. The evidence that long-term PPI use increases the risk of pneumonia and hip fractures is still inconclusive and a matter of debate [10, 13-23, 25, 26]. 

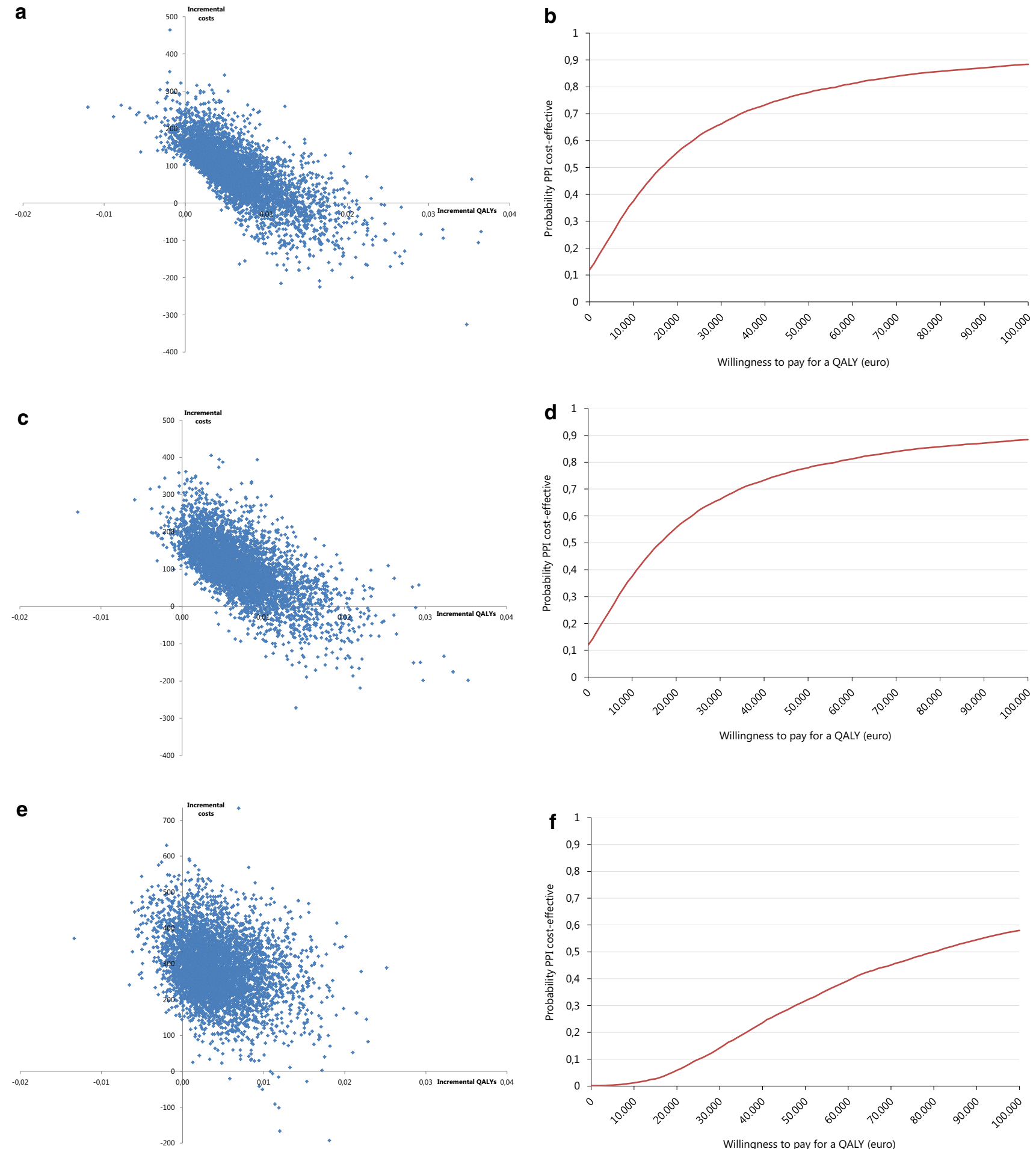

Fig. 2 Monte-Carlo simulations and cost-effectiveness acceptability curves for proton pump inhibitor (PPI) co-medication in low-dose acetylsalicylic acid (LDSA) users at increased upper gastrointestinal risk. Panels in the left column (a, c, e): scatterplots that present the results of the Monte-Carlo simulations. One dot represents one iteration of the Monte-Carlo simulation. The $Y$-axis states the

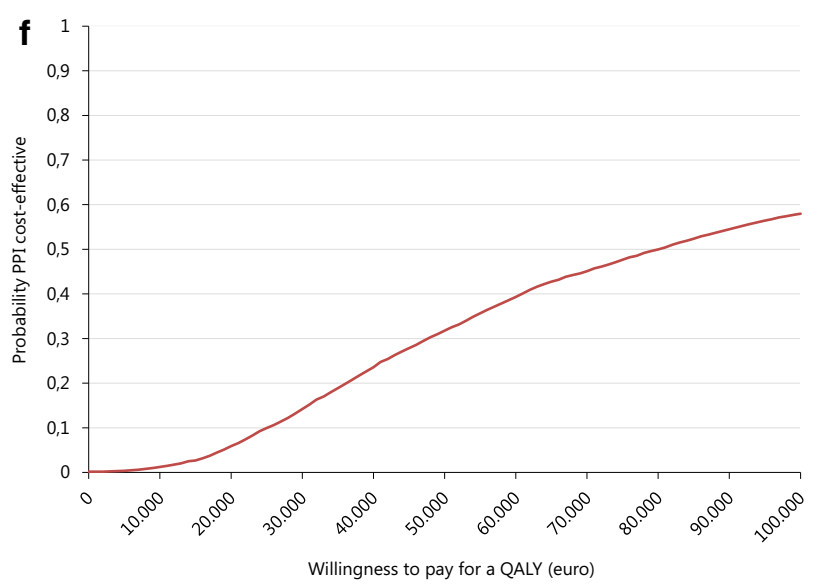

incremental costs of adding a PPI compared with no PPI. The $X$ axis represents the incremental quality-adjusted life-years (QALYs) of a PPI compared with no PPI. Panels in the right column $(\mathbf{b}, \mathbf{d}, \mathbf{f})$ : cost-effectiveness analysis (CEA) curves. The probability that the incremental costs per QALY are less than or equal to the costeffectiveness thresholds of the $X$-axis is stated on the $Y$-axis 

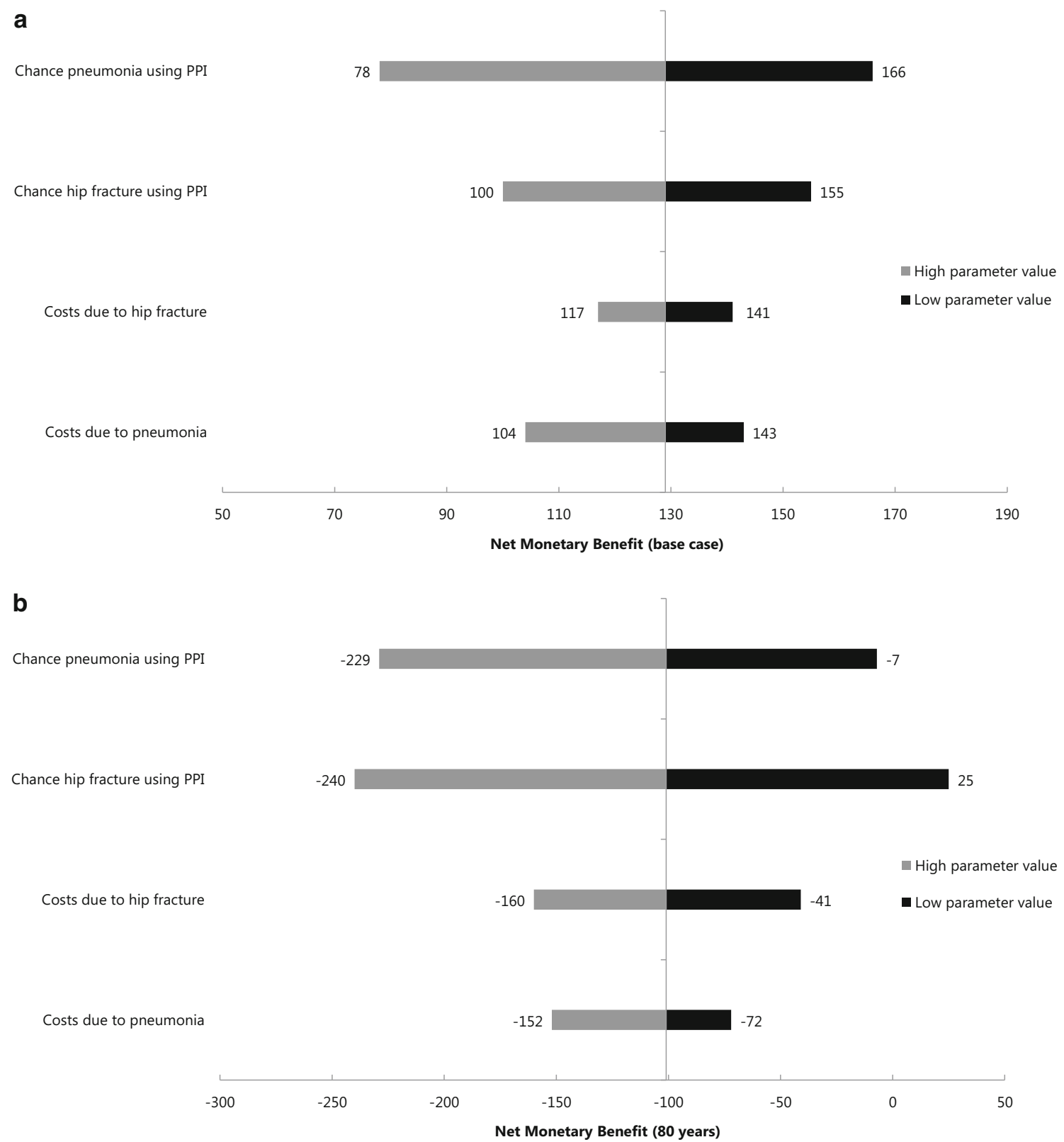

Fig. 3 Tornado diagram of the one-way sensitivity analysis for the effects of different assumptions for the risks and costs of the adverse effects: base case (a) and 80-year-old low-dose acetylsalicylic acid users (b). A high parameter value means that a higher parameter value

Therefore, sensitivity analyses were performed to show the separate effects of assumptions on the chance of potential adverse effects for the NMB on the cost effectiveness of PPI co-medication for the base case and for 80 years and older patients (Fig. 3). These analyses showed high uncertainties for the likelihood of adverse effects for both age categories. The uncertainties for costs due to pneumonia and hip fractures were higher for patients 80 years and older. This can be explained by higher basal risk levels of hip fracture and pneumonia in very old patients: even a (95th percentile of the confidence interval from the deterministic value) was chosen than the deterministic value for the analysis, and vice versa for a low parameter value (5th percentile). PPI proton pump inhibitor

small risk increase due to PPI use causes a substantial increase in effect compared with younger age categories.

Adding PPI co-medication to Dutch LDASA users at UGI risk without actual gastroprotection (19\% of all users) on the basis of this strategy in 2014 would have resulted in a BIA for 1 year of $€ 1,280,478$. The data also suggest that measures to enhance guideline adherence to prescribe gastroprotective medication in LDASA users, including the introduction of a Health Care Inspectorate indicator for community pharmacists in 2011 , has led to a considerable 
Table 2 Budget impact analysis (BIA) after 1 year for proton pump inhibitor co-medication in those low-dose acetylsalicylic acid users at increased upper gastrointestinal risk without proper co-medication in The Netherlands

\begin{tabular}{lccc}
\hline Age category & $\begin{array}{l}\text { Absolute numbers of } \\
\text { LDASA users at UGI risk }\end{array}$ & $\begin{array}{l}\text { Cost difference between } \\
\text { PPI and no PPI addition }(€)\end{array}$ & $\begin{array}{l}\text { Total BIA of } \\
\text { implementing PPI ( } € \text { ) }\end{array}$ \\
\hline $60-69$ years & 1300 & -22.39 & $-29,107$ \\
$70-79$ years & 14,126 & 17.28 & 244,097 \\
$\geq 80$ years & 55,610 & 19.16 & $1,065,488$ \\
All $\geq 60$ years & 71,036 & & $1,280,478$ \\
\hline
\end{tabular}

BIA budget impact analysis, LDASA low-dose acetylsalicylic acid, PPI proton pump inhibitor, UGI upper gastrointestinal

increase in the use of gastroprotective medication and of PPIs in particular in recent years [8, 9, 30]. In this respect, pharmacist-led interventions aimed at initiating PPI treatment have been found to be effective instruments in tackling under prescription [41-44].

The present study has several strengths. In contrast to earlier cost-effectiveness studies, the present study focused on both PPI benefits and risks in older LDASA users at risk of UGI adverse effects and compared the strategy of PPI co-medication with no PPI use. Thus, adverse effects attributable to long-term PPI use were taken into account. As the strength of evidence for the two main adverse effects for PPIs differs, sensitivity analyses were applied to elucidate their influence on our results. Campylobacteriosis was not considered because the incidence is much lower than the modelled adverse effects. In addition, the evidence on campylobacteriosis is weaker and the related expenses are also less pronounced. Furthermore, the analyses were performed for three different age categories of LDASA users at increased UGI risk according to actual recommendations. Finally, whenever possible the risks were modelled time and age dependently.

There are also a number of caveats and limitations. First, we assumed the risks for PPI co-medication to result from continuous use during 5 years at a compliance rate of $68 \%$ as a reflection of actual clinical practice. In the case of a lower compliance rate of $20 \%$, the impact of PPI adverse effects would have been lower but LDASA-induced adverse effects would have been higher, resulting in an ICUR of $€ 73,286$ for the base-case analysis. In the case of a higher compliance rate of $100 \%$, the reverse would apply, resulting in an ICUR of $€ 9391$ for the base-case analysis. However, according to the ICURs, the influence of LDASA-induced adverse effects seems to be much higher than that of PPI adverse effects. In addition, full adherence was assumed for LDASA use. This may have led to an overestimation of the preventable risks of PPI use. However, one must take patients' actual adherence to treatment into account when interpreting the study results.

Second, only the increased risks of hip fractures was included, whereas PPI might also increase the risks of other fractures. Thus, the risk of PPI-induced adverse effects may have been underestimated, potentially leading to an overestimation of the cost effectiveness of PPI co-medication. Third, as with all similar modelling studies, the present study is limited by the assumptions made in the model. Risk ratios for developing adverse effects were collected from heterogeneous observational studies in the absence of randomised clinical trial data. However, by preferentially using meta-analyses and studies published in high-quality journals, the model was constructed as accurately as possible.

Fourth, a discount rate of $4.0 \%$ for costs and $1.5 \%$ for effects was used in this study. In the literature, there is considerable debate about the use of discount rates, their height, and also about the difference between the rates for costs and effects [32]. The scenario analysis showed that when a discount rate of $4 \%$ was applied to both outcomes, the resulting ICURs slightly increased because of fewer effects gains and somewhat lower incremental effects. Using a rate of $1.5 \%$ for both outcomes also led to higher ICURs (not shown here) than in the base-case scenario.

Finally, with respect to the BIA, it is important to note that the prices used to calculate the BIA reflect the real prices used by the healthcare insurers. At present in the Netherlands these prices are rather low due to the power of health insurers to impose stiff price-restricting measures that may differ by insurer and are not fully transparent. We believe that the prices used in the present study are the best available under these circumstances.

\section{Conclusion}

For LDASA users between 60 and 80 years of age at increased risk of UGI adverse effects, the use of PPI comedication is likely to be a cost effective approach, even when PPI-induced adverse effects are taken into account. However, with increasing age the cost effectiveness declines, predominantly due to increased risks for PPI-induced adverse effects. 
Acknowledgements Parts of this research have been presented during the International Society for Pharmacoeconomics and Outcomes Research (ISPOR) 18th Annual European Congress in Milan, Italy and during the Pharmaceutical Care Network Europe (PCNE) 2016 Working Symposium in Hillerød, Denmark.

\section{Compliance with Ethical Standards}

Ethical approval This study, using computer simulations (Markov model) and anonymised medication dispensing data, does not contain any studies with human participants or animals performed by any of the authors. Therefore, it did not require ethical approval according to current Dutch legislation.

Funding An unrestricted Grant was received from Royal Dutch Pharmacists Association (KNMP), The Hague, The Netherlands. However, the funding body had no role in the analysis nor interpretation of the findings of this article.
Conflict of interest Martina Teichert is an employee of KNMP. Sek Hung Chau, Reinier L. Sluiter, Wietske Kievit, Michel Wensing and Jacqueline G. Hugtenburg declare no conflicts of interest.

Open Access This article is distributed under the terms of the Creative Commons Attribution-NonCommercial 4.0 International License (http://creativecommons.org/licenses/by-nc/4.0/), which permits any noncommercial use, distribution, and reproduction in any medium, provided you give appropriate credit to the original author(s) and the source, provide a link to the Creative Commons license, and indicate if changes were made.

\section{Appendix A}

See Table 3.

Table 3 Acetylsalicylic acid model

\begin{tabular}{|c|c|c|c|}
\hline Parameter (3-month cycles) & Probability & $95 \% \mathrm{CI}$ & Source \\
\hline \multicolumn{4}{|l|}{ Strategy dependent } \\
\hline Probability to develop dyspepsia & 0.026 & $0.01-0.04$ & {$[29]$} \\
\hline Probability to develop PUB & $\begin{array}{c}\text { Age and cycle } \\
\text { dependent }\end{array}$ & & {$[34]$} \\
\hline Probability that dyspepsia resolves & 0.5 & $0.45-0.55$ & {$[45]$} \\
\hline Probability to develop dyspepsia post-GI bleeding & 0.05 & $0.01-0.07$ & [30] \\
\hline Probability that dyspepsia resolves post-GI bleeding & 0.61 & $0.55-0.68$ & {$[30]$} \\
\hline Probability of re-bleeding post-GI bleeding & 0.1 & $0.07-0.17$ & {$[30]$} \\
\hline Probability of pneumonia due to PPI & $\begin{array}{c}\text { Age and cycle } \\
\text { dependent }\end{array}$ & & {$[34]$} \\
\hline Probability of hip fracture due to PPI & $\begin{array}{c}\text { Age and cycle } \\
\text { dependent }\end{array}$ & & {$[34]$} \\
\hline Probability of PPI compliance & 0.68 & $0.2-1$ & {$[30]$} \\
\hline Risk ratio for pneumonia due to PPI use & 1.89 & $1.36-2.62$ & [18] \\
\hline Risk ratio for hip fracture due to PPI use (after 1 year) & 1.24 & $1.15-1.34$ & [46] \\
\hline Costs of PPI for 3 months & $€ 2.40$ & $2.00-10.00$ & {$[33]$} \\
\hline Standard prescription costs & $€ 6.00$ & & {$[33]$} \\
\hline First prescription costs & $€ 12.00$ & & {$[33]$} \\
\hline \multicolumn{4}{|l|}{ Strategy independent } \\
\hline See lifetables_-general mortality rate & $\begin{array}{c}\text { Age and cycle } \\
\text { dependent }\end{array}$ & & {$[34]$} \\
\hline Chance to die of PUB & 0.02 & $0.010-0.037$ & {$[30]$} \\
\hline Chance of death due to hip fracture & 0.25 & $0.15-0.35$ & {$[47]$} \\
\hline Chance of dyspepsia while on ASA & 0.050 & $0.01-0.08$ & [29] \\
\hline Chance of PUB while on LDASA & $\begin{array}{c}\text { Age and cycle } \\
\text { dependent }\end{array}$ & & {$[34]$} \\
\hline Chance of dyspepsia post-GI bleeding & $(2 \times \mathrm{PPI})=0.1^{\mathrm{a}}$ & & [30] \\
\hline Chance of re-bleeding post-bleeding & $(2 \times \mathrm{PPI})=0.2^{\mathrm{a}}$ & & [30] \\
\hline Utility for dyspepsia & 0.94 & $0.9-0.98$ & [29] \\
\hline Utility for persisting dyspepsia & 0.88 & $0.87-0.93$ & [29] \\
\hline Utility for GI bleeding & 0.94 & $0.88-0.97$ & [29] \\
\hline Utility post-GI bleeding & 0.98 & $0.95-1$ & [29] \\
\hline Utility for dyspepsia post-GI bleeding & 0.94 & $0.9-0.98$ & {$[30]$} \\
\hline Utility for persisting dyspepsia post-GI bleeding & 0.88 & $0.87-0.93$ & {$[30]$} \\
\hline
\end{tabular}


Table 3 continued

\begin{tabular}{|c|c|c|c|}
\hline Parameter (3-month cycles) & Probability & $95 \% \mathrm{CI}$ & Source \\
\hline Utility for no GI complications & 1 & & \\
\hline $\begin{array}{l}\text { Utility for no hip fracture; adults ( }>17 \text { years of age), men and post-menopausal women } \\
\text { with primary or secondary osteoporosis }\end{array}$ & 0.99 & $0.95-1$ & [48] \\
\hline $\begin{array}{l}\text { Disutility for } 1 \text { year after hip fracture; adults ( }>17 \text { years of age), men and post- } \\
\text { menopausal women with primary or secondary osteoporosis }\end{array}$ & 0.23 & $0.15-0.31$ & [48] \\
\hline Utility for pneumonia & 0.9 & $0.87-0.95$ & $\mathrm{~b}$ \\
\hline Costs for embolisation/surgery & $€ 1329.47$ & $600.00-2000.00$ & {$[30]$} \\
\hline Costs for blood transfusion & $€ 405.35$ & $200.00-600.00$ & {$[30]$} \\
\hline Costs for diagnostic endoscopy & $€ 343.79$ & $175.00-525.00$ & {$[30]$} \\
\hline Costs of gastroenterologist & $€ 72.00$ & $35.00-105.00$ & {$[30]$} \\
\hline Costs of general practitioner & $€ 28.00$ & $10.00-35.00$ & {$[30]$} \\
\hline Costs for 10-day hospital admission & $€ 4570.00$ & $2000.00-6000.00$ & {$[30]$} \\
\hline Costs for Helicobacter pylori test & $€ 3.50$ & $2.00-5.00$ & {$[30]$} \\
\hline Costs for $H$. pylori breathing test & $€ 63.92$ & $30.00-90.00$ & {$[30]$} \\
\hline Costs for intravenous PPI & $€ 163.61$ & $100.00-200.00$ & {$[30]$} \\
\hline Costs for 1-month PPI treatment & $€ 0.80$ & $0.67-3.33$ & {$[33]$} \\
\hline Costs for therapeutic endoscopy & $€ 850.00$ & $350.00-1200.00$ & {$[30]$} \\
\hline Costs for triple therapy & $€ 64.89$ & $40.00-90.00$ & {$[33]$} \\
\hline Costs for paracetamol (acetaminophen) & $€ 10.80$ & $7.50-15.00$ & {$[33]$} \\
\hline Costs for pneumonia & $€ 3899.00$ & $2911.00-5684.00$ & {$[35]$} \\
\hline Costs for hip fracture & $€ 21,000$ & $15,000.00-25,000.00$ & {$[36]$} \\
\hline Chance of embolisation/surgery & 0.09 & $0.02-0.22$ & {$[30]$} \\
\hline Chance to re-bleed within 3 months & 0.067 & $0.05-0.09$ & {$[30]$} \\
\hline Chance of ulcus ventriculi & 0.18 & $0.11-0.24$ & {$[30]$} \\
\hline Chance of need for blood transfusion & 0.60 & $0.20-0.90$ & {$[30]$} \\
\hline Chance of $H$. pylori positive & 0.48 & $0.42-0.92$ & {$[30]$} \\
\hline
\end{tabular}

$A S A$ acetylsalicylic acid, $C I$ confidence interval, GI gastrointestinal, $L D A S A$ low-dose acetylsalicylic acid, PPI proton pump inhibitor, $P U B$ peptic ulcer bleeding

${ }^{a}$ Assumption that the parameter is twice as large compared to the parameter while using a PPI. ${ }^{\mathrm{b}}$ Assumption

\section{References}

1. Van der Hooft CS, Dieleman JP, Siemes C, Aarnoudse A-JLHJ, Verhamme KMC, Stricker BHCH, et al. Adverse drug reactionrelated hospitalisations: a population-based cohort study. Pharmacoepidemiol Drug Saf. 2008;17:365-71.

2. Leendertse AJ, Egberts ACG, Stoker LJ, van den Bemt PMLA, HARM Study Group. Frequency of and risk factors for preventable medication-related hospital admissions in the Netherlands. Arch Intern Med. 2008;168:1890-6.

3. Hawkey CJ. Nonsteroidal anti-inflammatory drug gastropathy. Gastroenterology. 2000;119:521-35.

4. Rostom A, Dube C, Wells G, Tugwell P, Welch V, Jolicoeur E, et al. Prevention of NSAID-induced gastroduodenal ulcers. Cochrane Database Syst Rev. 2002;(4):CD002296. doi:10.1002/ 14651858.CD002296

5. Rostom A, Wells G, Tugwell P, Welch V, Dubé C, McGowan J. The prevention of chronic NSAID induced upper gastrointestinal toxicity: a Cochrane collaboration metaanalysis of randomized controlled trials. J Rheumatol. 2000;27:2203-14.

6. Warlé-van Herwaarden MF, Kramers C, Sturkenboom MC, van den Bemt PMLA, De Smet PAGM, Dutch HARM-Wrestling Task Force. Targeting outpatient drug safety: recommendations of the Dutch HARM-Wrestling Task Force. Drug Saf. 2012;35:245-59.

7. Numans ME, de Wit NJ, Dirven JAM, Heemstra-Borst CG, Hurenkamp GJB, Scheele ME, et al. NHG-Standaard Maagklachten (tweede herziening) [Dutch College of General Practitioners' (NHG) practice guideline "Gastric symptoms" (second revision)]. Huisarts Wet. 2013;1:26-35.

8. Warle-van Herwaarden MF, Koffeman AR, Valkhoff VE, 't Jong GW, Kramers C, Sturkenboom MC, et al. Time-trends in the prescribing of gastroprotective agents to primary care patients initiating low-dose aspirin or non-steroidal anti-inflammatory drugs: a population-based cohort study. Br J Clin Pharmacol. 2015;80:589-98.

9. De Jong HJI, Korevaar JC, van Dijk L, Voogd E, van Dijk CE, van Oijen MGH. Suboptimal prescribing of proton-pump inhibitors in low-dose aspirin users: a cohort study in primary care. BMJ Open. 2013;3(7). doi:10.1136/bmjopen-2013-003044.

10. Yang Y-X, Lewis JD, Epstein S, Metz DC. Long-term proton pump inhibitor therapy and risk of hip fracture. JAMA. 2006;296:2947-53.

11. Vestergaard P, Rejnmark L, Mosekilde L. Proton pump inhibitors, histamine $\mathrm{H} 2$ receptor antagonists, and other antacid medications and the risk of fracture. Calcif Tissue Int. 2006;79:76-83. 
12. Targownik LE, Lix LM, Metge CJ, Prior HJ, Leung S, Leslie WD. Use of proton pump inhibitors and risk of osteoporosisrelated fractures. CMAJ. 2008;179:319-26.

13. Ngamruengphong S, Leontiadis GI, Radhi S, Dentino A, Nugent K. Proton pump inhibitors and risk of fracture: a systematic review and meta-analysis of observational studies. Am J Gastroenterol. 2011;106:1209-18 (quiz 1219).

14. Yu EW, Bauer SR, Bain PA, Bauer DC. Proton pump inhibitors and risk of fractures: a meta-analysis of 11 international studies. Am J Med. 2011;124:519-26.

15. Moayyedi P, Yuan Y, Leontiadis G, CAG Clinical Affairs. Canadian Association of Gastroenterology position statement: hip fracture and proton pump inhibitor therapy-a 2013 update. Can J Gastroenterol. 2013;27:593-5.

16. Adams AL, Black MH, Zhang JL, Shi JM, Jacobsen SJ. Protonpump inhibitor use and hip fractures in men: a population-based case-control study. Ann Epidemiol. 2014;24:286-90.

17. Cea Soriano L, Ruigómez A, Johansson S, García Rodríguez LA. Study of the association between hip fracture and acid-suppressive drug use in a UK primary care setting. Pharmacotherapy. 2014;34:570-81.

18. Laheij RJF, Sturkenboom MCJM, Hassing R-J, Dieleman J, Stricker BHC, Jansen JBMJ. Risk of community-acquired pneumonia and use of gastric acid-suppressive drugs. JAMA. 2004;292:1955-60.

19. Gulmez SE, Holm A, Frederiksen H, Jensen TG, Pedersen C, Hallas J. Use of proton pump inhibitors and the risk of community-acquired pneumonia: a population-based case-control study. Arch Intern Med. 2007;167:950-5.

20. Sarkar M, Hennessy S, Yang Y-X. Proton-pump inhibitor use and the risk for community-acquired pneumonia. Ann Intern Med. 2008;149:391-8.

21. Eurich DT, Sadowski CA, Simpson SH, Marrie TJ, Majumdar SR. Recurrent community-acquired pneumonia in patients starting acid-suppressing drugs. Am J Med. 2010;123:47-53.

22. Eom C-S, Jeon CY, Lim J-W, Cho E-G, Park SM, Lee K-S. Use of acid-suppressive drugs and risk of pneumonia: a systematic review and meta-analysis. CMAJ. 2011;183:310-9.

23. De Groot MCH, Klungel OH, Leufkens HGM, van Dijk L, Grobbee DE, van de Garde EMW. Sources of heterogeneity in case-control studies on associations between statins, ACE-inhibitors, and proton pump inhibitors and risk of pneumonia. Eur $\mathbf{J}$ Epidemiol. 2014;29:767-75.

24. Bouwknegt M, van Pelt W, Kubbinga ME, Weda M, Havelaar AH. Potential association between the recent increase in campylobacteriosis incidence in the Netherlands and protonpump inhibitor use-an ecological study. Euro Surveill. 2014;19(32):21-6.

25. Jena AB, Sun E, Goldman DP. Confounding in the association of proton pump inhibitor use with risk of community-acquired pneumonia. J Gen Intern Med. 2013;28:223-30.

26. Panday K, Gona A, Humphrey MB. Medication-induced osteoporosis: screening and treatment strategies. Ther Adv Musculoskelet Dis. 2014;6:185-202.

27. Saini SD, Schoenfeld P, Fendrick AM, Scheiman J. Cost-effectiveness of proton pump inhibitor cotherapy in patients taking long-term, low-dose aspirin for secondary cardiovascular prevention. Arch Intern Med. 2008;168:1684-90 (discussion 1691).

28. Earnshaw SR, Scheiman J, Fendrick AM, McDade C, Pignone M. Cost-utility of aspirin and proton pump inhibitors for primary prevention. Arch Intern Med. 2011;171:218-25.

29. De Groot NL, van Haalen HGM, Spiegel BMR, Laine L, Lanas A, Focks JJ, et al. Gastroprotection in low-dose aspirin users for primary and secondary prevention of ACS: results of a cost-effectiveness analysis including compliance. Cardiovasc Drugs Ther. 2013;27:341-57.
30. De Groot NL, Spiegel BMR, van Haalen HGM, de Wit NJ, Siersema PD, van Oijen MGH. Gastroprotective strategies in chronic NSAID users: a cost-effectiveness analysis comparing single-tablet formulations with individual components. Value Health. 2013;16:769-77.

31. Briggs AH, Claxton K, Sculpher MJ. Decision modelling for health economic evaluation. Oxford: Oxford University Press; 2006.

32. Drummond M, Sculpher MJ, Torrance GW, O’Brien BJ, Stoddart GL. Methods for the economic evaluation of health care programmes. Oxford: Oxford University Press; 2005.

33. Zorginstituut Nederland. Medicijnkosten. [cited 2015 July 5]. http://www.medicijnkosten.nl/. Accessed 5 July 2015.

34. Centraal Bureau voor de Statistiek [Dutch Statistics]. Ziekenhuisopnamen; geslacht, leeftijd en diagnose-indeling ICD9. [Hospital admissions; gender, age, and diagnosis (ICD9)]. 2013. http://statline.cbs.nl/. Accessed 5 July 2014.

35. Spoorenberg SMC, Bos WJW, Heijligenberg R, Voorn PGP, Grutters JC, Rijkers GT, et al. Microbial aetiology, outcomes, and costs of hospitalisation for community-acquired pneumonia; an observational analysis. BMC Infect. Dis. 2014;14:335.

36. Stichting VeiligheidNL [Foundation VeiligheidNL], Amsterdam. Letsel Informatie Systeem 2012 [Injury Information System 2012].

37. College voor zorgverzekeringen [Health care insurance board]. Richtlijnen voor farmaco-economisch onderzoek, geactualiseerde versie [Guidelines for pharmaco-economic research, updated version]. Diemen:College voor zorgverzekeringen; 2006 Mar.

38. Sullivan SD, Mauskopf JA, Augustovski F, Jaime Caro J, Lee $\mathrm{KM}$, Minchin M, et al. Budget impact analysis-principles of good practice: report of the ISPOR 2012 Budget Impact Analysis Good Practice II Task Force. Value Health. 2014;17:5-14.

39. WHO Collaborating Centre for Drug Statistics Methodology. Guidelines for ATC classification and DDD assignment 2013. Oslo: WHO Collaborating Centre for Drug Statistics Methodology; 2012.

40. Do PPIs have long-term side effects? Nexium and the other proton-pump inhibitors are great at reducing stomach acid, but that might have some unintended consequences. Harv Health Lett. 2009;34:4-5.

41. Teichert M, Griens F, Buijs E, Wensing M, De Smet PAGM. Effectiveness of interventions by community pharmacists to reduce risk of gastrointestinal side effects in nonselective nonsteroidal anti-inflammatory drug users. Pharmacoepidemiol Drug Saf. 2014;23:382-9.

42. Ivers N, Jamtvedt G, Flottorp S, Young JM, Odgaard-Jensen J, French SD, et al. Audit and feedback: effects on professional practice and healthcare outcomes. Cochrane Database Syst Rev. 2012;6:CD000259.

43. Avery AJ, Rodgers S, Cantrill JA, Armstrong S, Cresswell K, Eden $\mathrm{M}$, et al. A pharmacist-led information technology intervention for medication errors (PINCER): a multicentre, cluster randomised, controlled trial and cost-effectiveness analysis. Lancet. 2012;379:1310-9.

44. Ibañez-Cuevas V, Lopez-Briz E, Guardiola-Chorro MT, NSAID induced Gastropathy Prevention Programme Group. Pharmacist intervention reduces gastropathy risk in patients using NSAIDs. Pharm World Sci. 2008;30:947-54.

45. Saini SD, Fendrick AM, Scheiman JM. Cost-effectiveness analysis: cardiovascular benefits of proton pump inhibitor co-therapy in patients using aspirin for secondary prevention. Aliment Pharmacol Ther. 2011;34:243-51. doi:10.1111/j.1365-2036. 2011.04707.x.

46. Ye X, Liu H, Wu C, et al. Proton pump inhibitors therapy and risk of hip fracture: a systematic review and meta-analysis. Eur $\mathrm{J}$ 
Gastroenterol Hepatol. 2011;23:794-800. doi:10.1097/MEG. 0b013e328348a56a.

47. Osteoporose, tweede herziene richtlijn [Guideline Osteoporosis, second revision]. Utrecht: Kwaliteitsinstituut voor de Gezondheidszorg CBO; 2003.
48. Peasgood T, Herrmann K, Kanis JA, Brazier JE. An updated systematic review of Health State Utility Values for osteoporosis related conditions. Osteoporos Int. 2009;20:853-68. doi:10.1007/ s00198-009-0844-y. 